\title{
Short-Term Impact of the EU-Japan EPA: The Case of Wine Exports from France, Italy, and Spain to Japan
}

\author{
Massimiliano Porto \\ Associate Professor, Kobe University
}

\begin{abstract}
In February 2019, the Economic Partnership Agreement between the European Union and Japan was enforced, liberalising most of the bilateral trade. For example, Japan eliminated the duties on European products such as chemicals, textiles, clothing and wine immediately upon entry into force of the agreement. In this study, we attempt to quantify the short-term effect of the EPA on European wine exports to Japan. We fit a seasonal auto regressive integrated moving average (SARIMA) model to the monthly exports of wine from France, Italy, and Spain to Japan up to the month prior to the activation of the EU - Japan EPA. Subsequently, we use the estimated models to forecast twelve months ahead starting from February 2019, i.e., from the first month of implementation of the EU - Japan EPA. Finally, we compare the forecasts with the observed values for the same period. The results show that our forecasts do not outperform the observed values. Consequently, we conclude that the positive difference between the observed values and the forecast is due to the effect of the agreement.
\end{abstract}

Keywords: SARIMA, outliers, EU - Japan EPA, forecasts

\section{Introduction}

After the second world war, the General Agreement on Tariffs and Trade (GATT), a provisional agreement replacing the never-established International Trade Organization (ITO), came into force. It has proven to be an efficient forum for the contracting parties to negotiate reciprocal trade liberalization through tariff reduction. In the Uruguay Round, the World Trade Organization (WTO), a structured international organization, was established as an improved version of the GATT (Hartman, 2013, p. 412) to oversee the multilateral trading system. ${ }^{1}$

However, since the end of the XX century, WTO members have found more obstacles while pursuing trade liberalisation. The main difficulty in reaching an agreement under the WTO lies not so much in the number of its members (164 as of July 2016), as it does in the marked differentiation of interests that emerged among three groups of members: developed countries, emerging economies, and least developed countries. In fact, at the end of 1994, 128 countries were contracting parties to the GATT, while there were more than 80 during the 1980s. However, the GATT at that time was dominated by a few developed countries that could easily set the agenda. On the other hand, divergent interests among developed countries, emerging economies and least developed countries make it difficult to reach an agreement

\footnotetext{
${ }^{1}$ Round is the name used for concerted, multilateral negotiations under the GATT/WTO system.
} 
since all the items in a negotiation need to be agreed upon, or, in WTO's terminology, nothing is agreed until everything is agreed (single undertaking principle).

The GATT/WTO system is based on the principle of the most favoured nation (MFN), that is treating other WTO members equally. In other words, if a WTO member grants an advantage to a country, it has to provide the same advantage to all WTO members (Art. I GATT). However, there are two exceptions to this principle: 1) the Enabling Clause, i.e., developed members can accord preferential treatment unilaterally to goods imported from developing countries and least developed countries (LDCs) without having to extend such better treatment to other members; and 2) article XXIV GATT that states that a member may provide preferential treatment only to some countries within a free trade area or a customs union without having to extend such better treatment to all members. Therefore, article XXIV provides a legal basis under the GATT/WTO system for countries to further liberalise trade among themselves through the negotiation of bilateral or regional Free Trade Agreements (FTAs). The frozen talks at the Doha Round are recognized as a main reason behind the surge in the number of FTAs concluded in recent years.

The European Union (EU) and Japan have been among the most active countries in seeking trade partnerships. Even though the EU has always been a supporter of the multilateral trading system, the 2006 European Commission (EC) Working Document Global Europe paved the way for a strong commitment of the EU in FTA negotiations. The document identifies key economic criteria for an FTA partner such as market potential, the level of protection against EU export interests, and EU potential partners' negotiations with EU competitors (European Commission, 2006). Japan laid the foundation of its FTA strategy in 2002 when the Ministry of Foreign Affairs identified the economic and political advantages of promoting FTAs, such as the expansion of export markets and an increase in bargaining power in WTO negotiations

(Ministry of Foreign Affairs of Japan, 2002). In 2004, in the Basic Policy toward Further Promotion of Economic Partnerships Japan considered FTAs as a tool not only to contribute to the development of its economy but also to complement the multilateral trading system (Council of Ministers of Japan on the Promotion of Economic Partnership, 2004). ${ }^{1}$ On March 25,2013 , the EU and Japan officially launched trade negotiations aimed at concluding a bilateral FTA that the EC defined as a strategic priority (European Commission, 2015, p. 31). On December 8, 2017, the negotiations were finalized, and the agreement entered into force on February 1, 2019.

The agreement achieved a high degree of trade liberalisation. The EU has liberalised 99\% of tariff lines and 100\% of imports, whereas Japan has liberalised $97 \%$ and $99 \%$, respectively. Most of the duties were eliminated immediately upon the FTA's entry into force. However, for sensitive products, the parties agreed on a gradual reduction of tariff over a period that is

\footnotetext{
1 EPA stands for Economic Partnership Agreement. The Japanese government distinguishes between FTA and EPA. For example, the Japan External Trade Organization (JETRO) defines FTA as an international treaty to eliminate tariffs imposed between countries or regions and to abolish regulation in the field of foreign investments in trade in services whereas EPA is defined as an international treaty to deregulate regulations for investments and for immigration control in addition to the contents of an FTA (JETRO, 2008). In this view, EPAs are broader agreements that include the contents of FTAs. However, given that many of the FTAs that have been recently signed are comprehensive agreements more than simple tariff elimination agreements, the distinction between FTA and EPA is not neat. Therefore, in this paper we use the terms FTA and EPA interchangeably.
} 
called the transition period. The transition period is usually agreed upon to allow domestic firms to reorganize to face stronger competition from the partner's firms. For example, EU tariffs on passenger cars from Japan will be gradually phased out over a period of seven years.

European products that enter duty-free in Japan upon implementation of the agreement include chemicals, textiles and clothing, metals, ceramics and glass, cosmetics, plastics, jewellery and precious stones, and wine. Elementary economics tells us that tariff removal on a product will increase its imports because it becomes cheaper for domestic consumers. In trade policy analysis, the gravity model of international trade is the empirical workhorse model to estimate the effect of FTAs. However, the gravity model of trade requires a considerable amount of data and number of years after the implementation of the policy to produce a significant estimation. In this study, we attempt to quantity the short-term effect of a zero-tariff on European exports to Japan, i.e., in the first twelve months after the entry into force of the agreement. We will limit our analysis to the effects of the EPA on wine exports from the largest wine exporters, i.e., France, Italy, and Spain. Japan immediately eliminated $15 \%$ tariff on wine imports from the EU after the EPA entered into force.

We will use the following approach: we will fit a seasonal auto regressive integrated moving average (SARIMA) model to the monthly exports of wine up to the month prior to the entry into force of the EU - Japan EPA. Subsequently, we will forecast twelve months ahead of the exports starting from February 2019, i.e., the first month of implementation of the EU - Japan EPA. Finally, we will compare the forecasts with the observed values for the same period.

The rest of the paper is organized as follows. Section 2 describes the data of wine exports from France, Italy, and Spain to Japan from January 2002 to January 2020. Section 3 describes the methodology applied. Section 4 comments on the results of our analysis. Finally, section 5 concludes. ${ }^{1}$

\section{Data Description}

Monthly time series data for wine exports (HS 2204) of France, Italy, and Spain to Japan from January 2002 to January 2020 were downloaded from Eurostat (DS-016894) on April 17, 2020 (last update March 18, 2020).

Figure 1a plots the wine exports from France to Japan. Wine exports from France to Japan range from a minimum of EUR 14.8 million in August 2004 to a maximum of EUR 74 million in October 2018, with an average value of EUR 35 million. Figure 1 b shows the seasonal pattern in the data. Figure 1c plots wine exports from Italy to Japan.

Wine exports from Italy to Japan range from a minimum of EUR 4 million in January 2006 to a maximum of EUR 19 million in July 2019, with an average value of EUR 11 million. Figure 1d shows the seasonality in the data.

Finally, we conclude with the data for Spain. Before describing the data for the wine exports from Spain to Japan, it is necessary to explain an adjustment that has been made to the data. In March 2013, a value of EUR 36 million is reported. We investigated this value because it is

\footnotetext{
1 The following analysis has been implemented with R. The following packages have been used for the analysis: readxl (Wickham and Bryan, 2019) to import the data in Excel format; ggplot2 (Wickham, 2009), zoo (Zeileis and Grothendieck, 2005), ggpubr (Kassambara, 2019) for graphical analysis; tsoutliers (de Lacalle, 2019) for outliers analysis; tseries (Trapletti and Hornik, 2017) for statistical tests; forecast (Hyndman et al., 2019; Hyndman and Khandakar, 2008) for seasonal ARIMA model and forecasts.
} 
extremely high compared to the rest of the observed data. First, we observed the value in euros and the respective quantity of wine exports from Spain to Japan for the months of February, March, and April 2013. In February 2013, Spain exported wine to Japan for EUR 5.6 million for a quantity in $100 \mathrm{~kg}$ equal to 26911. The value in euros in March is 36 million and the quantity in $100 \mathrm{~kg}$ is 27036. In April 2013, Spain exported wine to Japan for EUR 8 million for a quantity in $100 \mathrm{~kg}$ equal to 35479 . The large difference in the value hardly allows to speculate that the value reported in March is due to an increase in value per kg exported. However, a second check was implemented by comparing the monthly data for March 2013 reported by Eurostat with the amount reported by COMTRADE. COMTRADE reports USD 7 million for March 2013, USD 7.4 million in February and USD 10.6 million in April. As a result, we conclude that EUR 36 million reported in March 2013 by Eurostat is suspicious, and we replaced it as follows:

$$
\text { VALUEMAR2013 }=\frac{\text { QUANTITYMAR2013 } \times \text { VALUEFEB2013 }}{\text { QUANTITYFEB2013 }}
$$

Figure 1e shows the adjusted data. We observe that another value stands out in November 2013. The value reported is EUR 14.5 million, which represents the largest amount exported by Spain in a month. We followed the above steps for verification of this value as well but it remains consistent in the cross-analysis. For example, COMTRADE reports USD 19.6 million, which is consistent given the exchange rate between euro and dollar. The minimum monthly value from January 2002 is EUR 1.1 million and is recorded in June 2003. The average value exported is EUR 4.8 million. Figure $1 \mathrm{f}$ shows the seasonal pattern in the data. Additionally, it is evident from figure $1 \mathrm{f}$ that we have an outlier in November 2013.

Figure 1 Wine exports from France, Italy, and Spain to Japan, January 2002 - January 2020 (EUR)

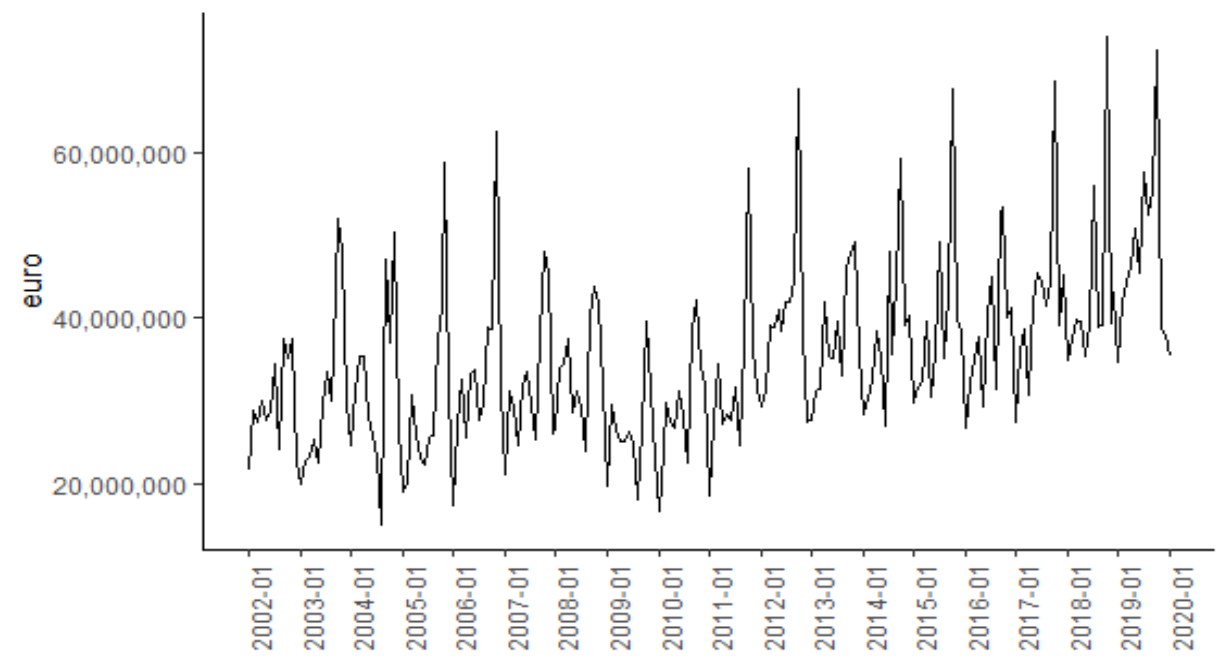

(a) France - Series 


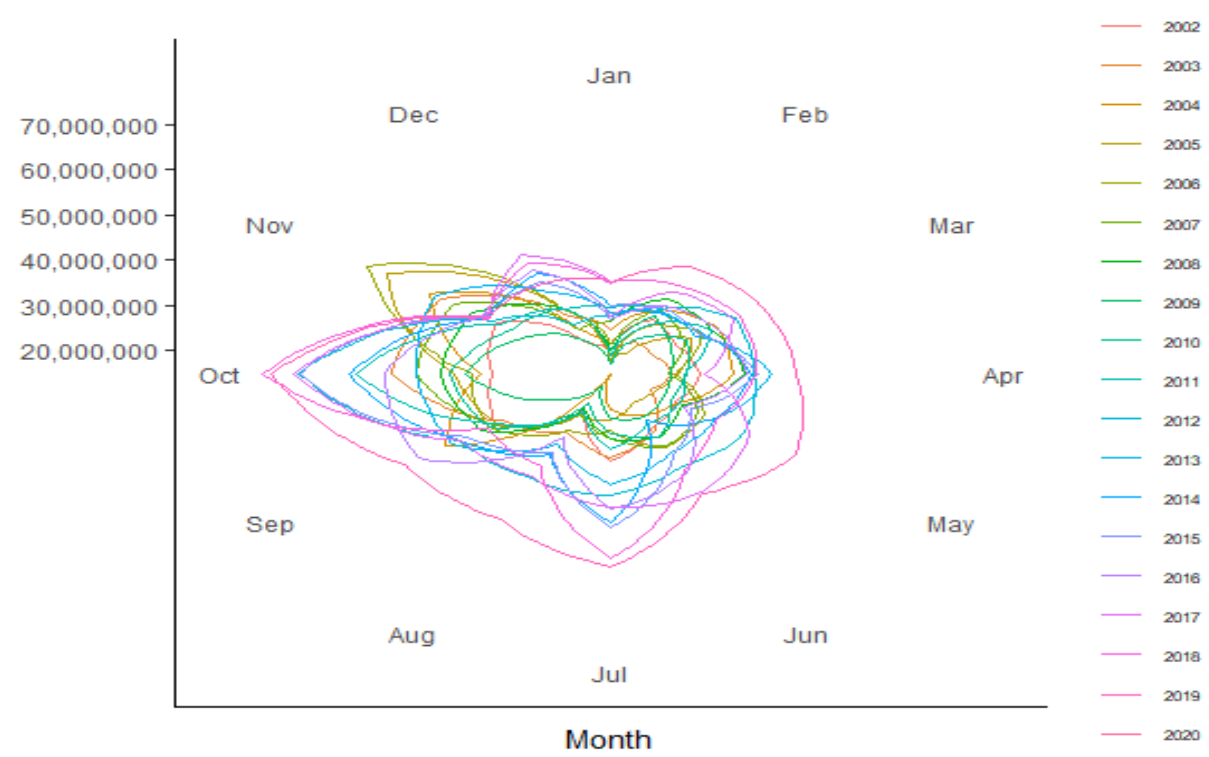

\section{b) France - Seasonality}

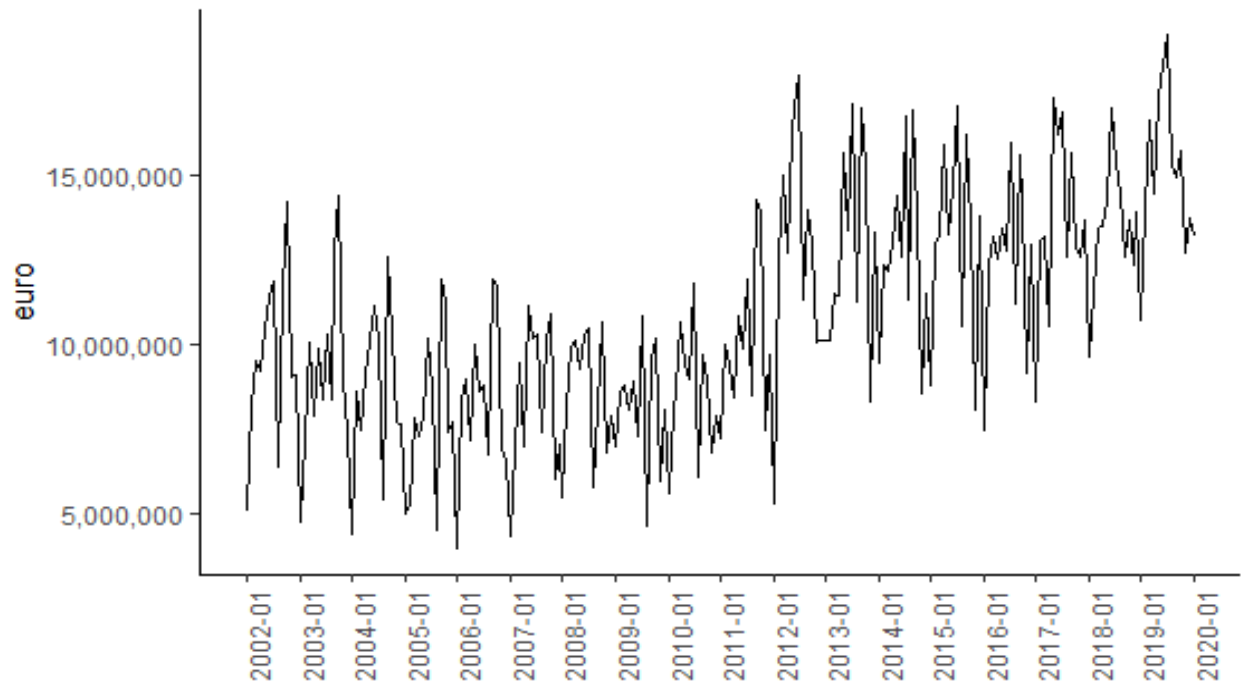

(c) Italy - Series 


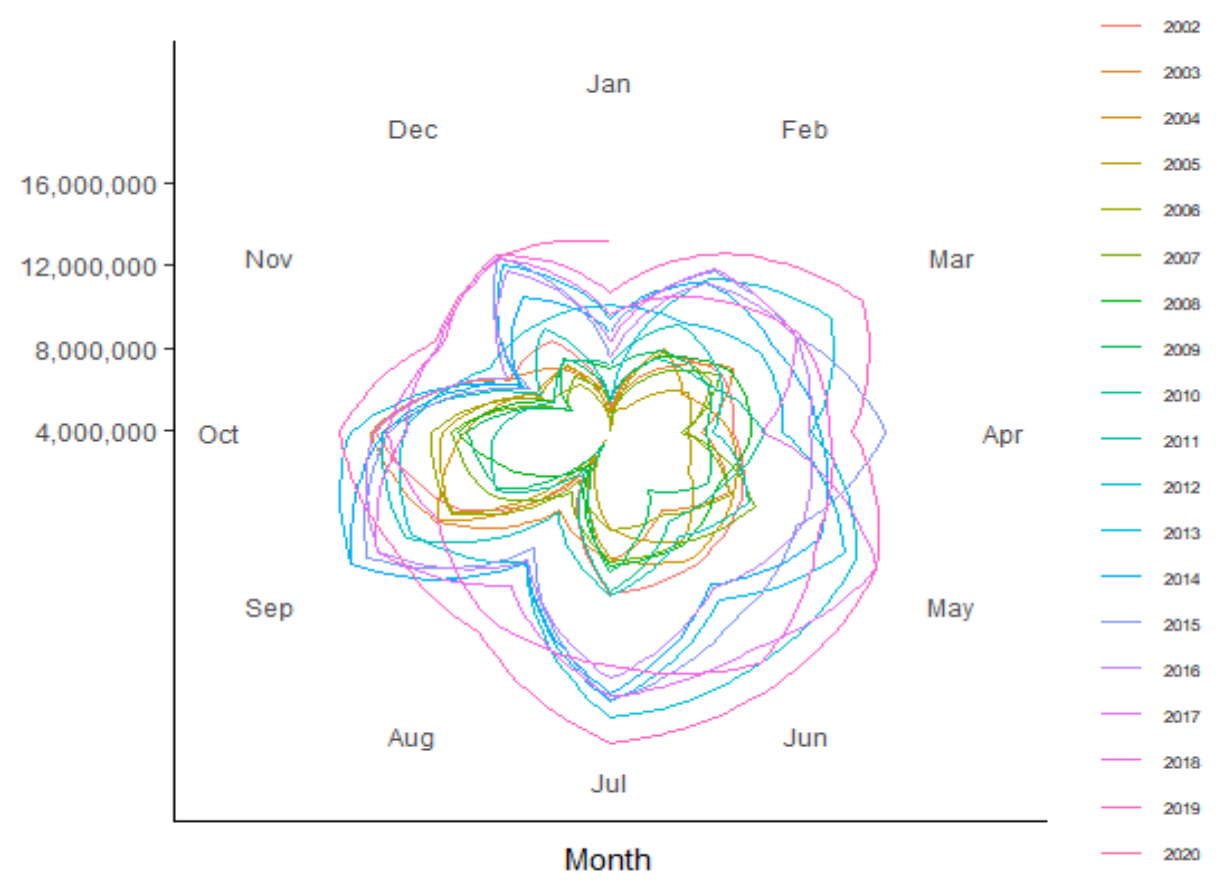

\section{(d) Italy - Seasonality}

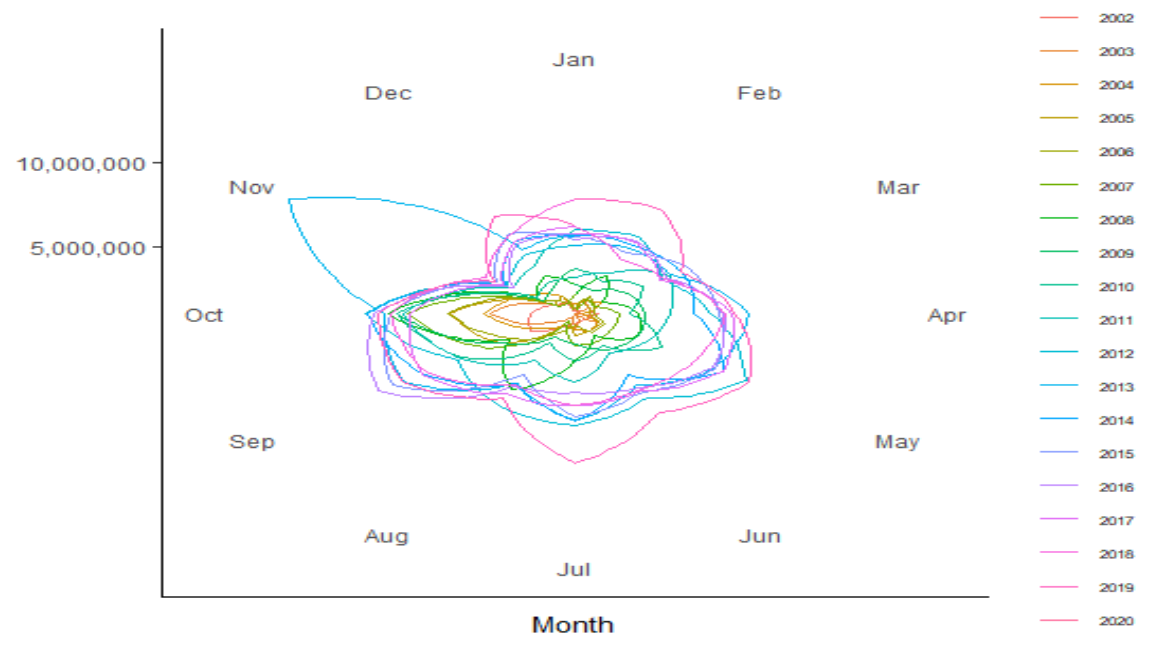

\section{(e) Spain - Series}




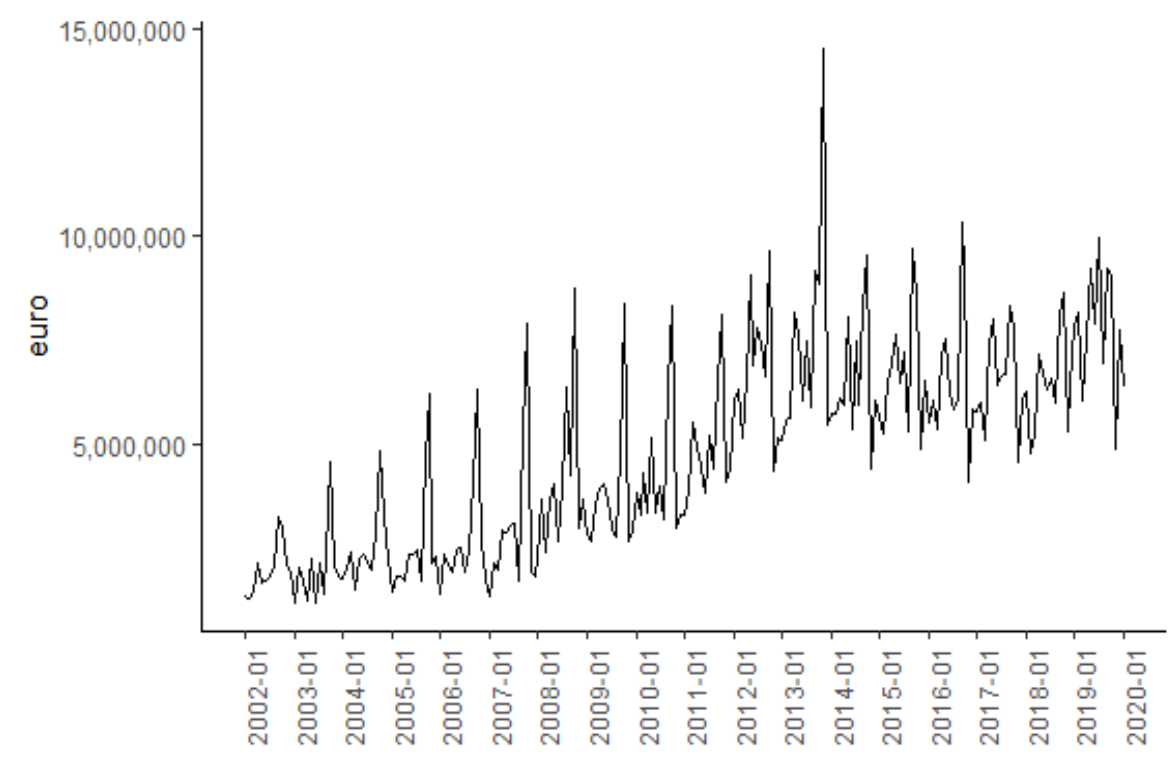

(f) Spain - Seasonality

\section{Methodology}

We model the wine exports from France, Italy, and Spain to Japan using a seasonal ARIMA process, or SARIMA. In ARIMA $(\boldsymbol{p}, \boldsymbol{d}, \boldsymbol{q})(\boldsymbol{P}, \boldsymbol{D}, \boldsymbol{Q})_{\boldsymbol{s}}$, where $(\boldsymbol{p}, \boldsymbol{d}, \boldsymbol{q})$ represents the non-seasonal part of the model and $(\boldsymbol{P}, \boldsymbol{D}, \boldsymbol{Q})$ represents the seasonal part of the model, $p$ is the order of nonseasonal autoregressive terms, $d$ is the order of non-seasonal differencing, $q$ is the order of non-seasonal moving average terms, $P$ is the order of seasonal autoregressive terms, $D$ is the order of seasonal differencing, $Q$ is the order of seasonal moving average terms, and $s$ is the span of the seasonality. An $\boldsymbol{A R I M A}(\boldsymbol{p}, \boldsymbol{d}, \boldsymbol{q})(\boldsymbol{P}, \boldsymbol{D}, \boldsymbol{Q})_{\boldsymbol{s}}$ has the following polynomial form:

$$
\Phi_{P}\left(B^{s}\right) \phi_{p}(B)\left(1-B^{s}\right)^{D}(1-B)^{d} y_{t}=\Theta_{Q}\left(B^{s}\right) \theta_{q}(B) \varepsilon_{\mathrm{t}}
$$

where $B$ is the back-shift operator and $\boldsymbol{\varepsilon}_{\boldsymbol{t}}$ is a white-noise process, and

$$
\phi_{p}(B)=1-\phi_{1} B-\cdots-\phi_{p} B^{p}
$$




$$
\begin{gathered}
\Phi_{P}\left(B^{s}\right)=1-\Phi_{1} B^{s}-\Phi_{2} B^{2 s}-\cdots-\Phi_{P} B^{P s} \\
\theta_{q}(B)=1+\theta_{1} B+\cdots+\theta_{q} B^{q} \\
\Theta_{Q}\left(B^{s}\right)=1+\Theta_{1} B^{s}+\Theta_{2} B^{2 s}+\cdots+\Theta_{Q} B^{Q s}
\end{gathered}
$$

Economic shocks, strikes, occurrence of natural disaster, and policy changes are some examples of non-repetitive events that can affect time series data by producing outlying observations. Outliers can lead to model misspecification, biased parameter estimation, and poor forecasts (Kaiser and Maravall, 1999, p. 7). Consequently, outlier detection is an important part of the analysis of time series. We investigate five types of outliers: additive outliers (AO), temporary changes (TC), innovative outliers (IO), level shifts (LS) (Chen and Liu, 1993) and seasonal level shifts (SLS) (Kaiser and Maravall, 1999). AO and TC are related to the irregular component of the time series, LS are related to the trend-cycle component, SLS are related to the seasonal component, and finally, IO are the result of an outlier that simultaneously affects the trend-cycle and the seasonal components. Let $\boldsymbol{y}_{\boldsymbol{t}}^{*}$

$$
y_{t}^{*}=\sum_{j=1}^{k} \xi_{j}(B) \omega_{j} I_{t}^{\tau_{j}}+y_{t}
$$

be the observed series that contains $k$ outliers, where $\boldsymbol{y} \boldsymbol{t}$ follows an ARIMA process as in (1); $\boldsymbol{\omega}_{\boldsymbol{j}}$ denotes the initial impact of the outlier at time $\boldsymbol{t}=\boldsymbol{\tau}_{\boldsymbol{j}} ; \boldsymbol{I}_{\boldsymbol{t}}^{\boldsymbol{\tau}_{\boldsymbol{j}}}$ is an indicator variable such that it is 1 for $\boldsymbol{t}=\boldsymbol{\tau}_{\boldsymbol{j}}$ and 0 otherwise; $\boldsymbol{\xi}_{\boldsymbol{j}}(\boldsymbol{B})$ determines the dynamics of the outlier occurring at $\boldsymbol{t}=\boldsymbol{\tau}_{\boldsymbol{j}}$ as follows:

$$
\begin{aligned}
A O: \xi_{j}(B) & =1 \\
T C: \xi_{j}(B) & =\frac{1}{1-\delta B}, \quad 0<\delta<1 \\
I O: \xi_{j}(B) & =\frac{\bar{\theta}(B)}{\bar{\phi}(B)} \\
L S: \xi_{j}(B) & =\frac{1}{1-B} \\
S L S: \xi_{j}(B) & =\frac{1}{1-B^{s}}
\end{aligned}
$$

where $\overline{\boldsymbol{\theta}}=\boldsymbol{\Theta}_{Q}\left(\boldsymbol{B}^{\boldsymbol{s}}\right) \boldsymbol{\theta}_{q}(\boldsymbol{B})$ and $\overline{\boldsymbol{\phi}}=\boldsymbol{\Phi}_{\boldsymbol{P}}\left(\boldsymbol{B}^{\boldsymbol{s}}\right) \boldsymbol{\phi}_{\boldsymbol{p}}(\boldsymbol{B})\left(\mathbf{1}-\boldsymbol{B}^{\boldsymbol{s}}\right)^{\boldsymbol{D}}(\mathbf{1}-\boldsymbol{B})^{\boldsymbol{d}}$.

We take logarithms to stabilize the variance in the data observed for the exports of wine from France, Italy and, Spain to Japan. Consequently, we apply the outlier analysis to the series in logarithms. The series of France shows an AO recorded in August 2004 and an SLS from November 2007 (figure 2a). Figure 2b shows an LS from February 2002 in the series of Italy. 
Finally, figure 2c shows two AO in August 2008 and in November 2013 (as expected from our previous data description) and an LS from January 2012 in the data of Spain.

Figure 2 Outliers in wine exports from France, Italy, and Spain to Japan, January 2002

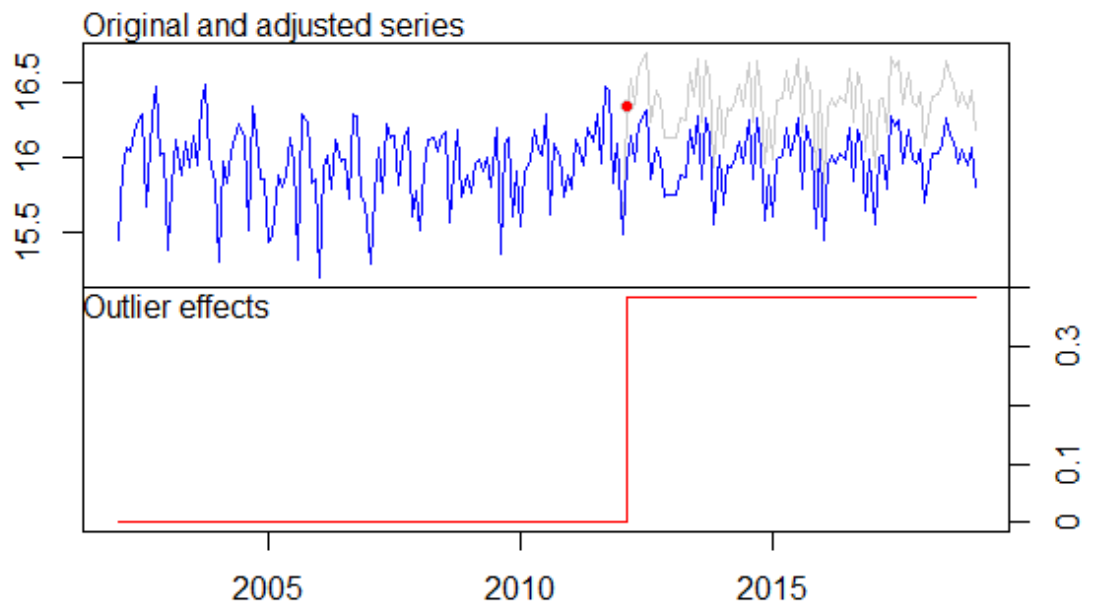

(a) France

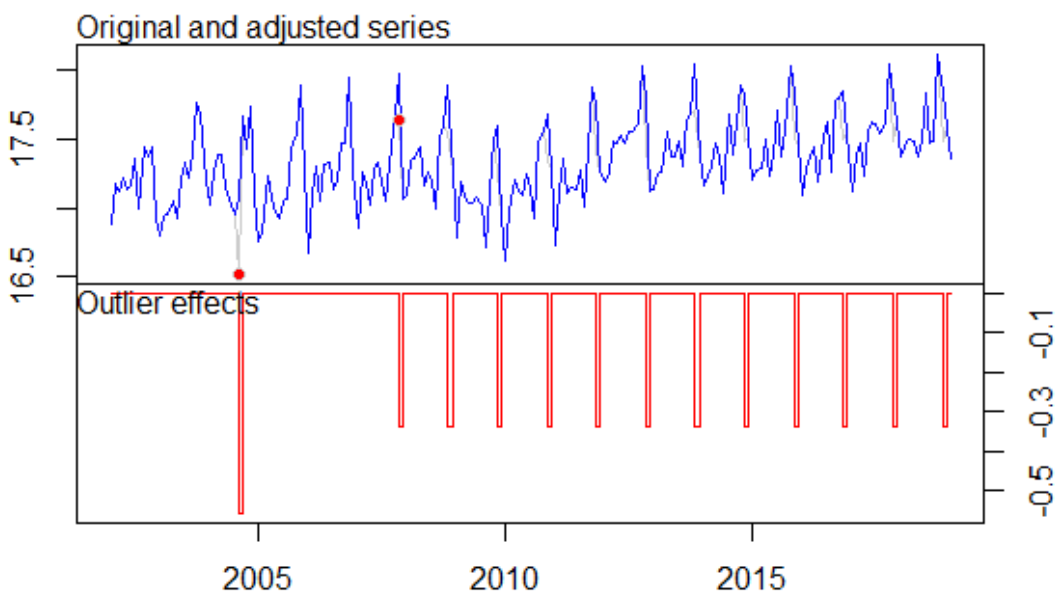

(b) Italy 


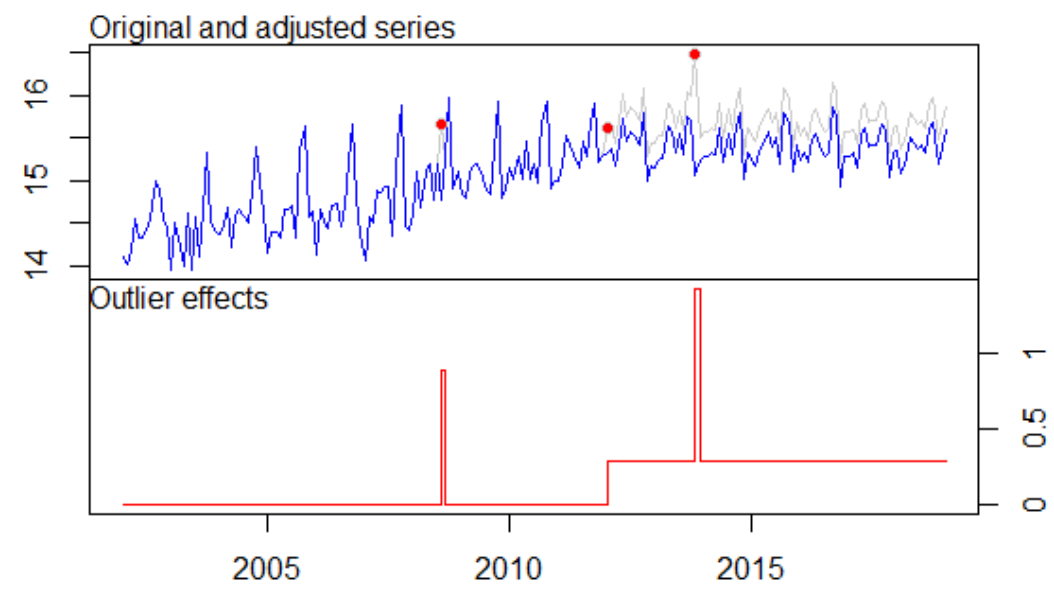

\section{(c) Spain}

Since the data analysis described in the previous section shows the presence of outliers, we control for them in the SARIMA model. A key role to select a model is played by the parsimony principle, i.e., by employing the smallest number of parameters for adequate representations (Box et al., 2008, p. 16). We consider models where $\boldsymbol{p}+\boldsymbol{d}+\boldsymbol{q}+\boldsymbol{P}+\boldsymbol{D}+\boldsymbol{Q} \leq \mathbf{6}$, with $\mathbf{0}<$ $\boldsymbol{d}+\boldsymbol{D} \leq 2 ; \boldsymbol{D} \neq \mathbf{2}$ for this analysis. Subsequently, we compare corrected Akaike's information criterion $(\boldsymbol{A I C})$ of the selected models and choose the model with minimum AICc because it is considered more parsimonious

$$
A I C_{c}=-2 \log (\text { Likelihood })+2 K+\frac{2 K(K+1)}{T-K-1}
$$

where $K$ is the number of parameters in the model and $T$ is the number of observations.

The model selected for wine exports of France is seasonal ARIMA(3,0,0)(0,1,1)[12] with drift and with an AO at $\boldsymbol{t}=\mathbf{3 2}$ and an SLS from $\boldsymbol{t} \geq \mathbf{7 1}$. The wine exports of Italy have been modelled as seasonal ARIMA(1,0,3)(0,1,1)[12], with an LS from $\boldsymbol{t} \geq \mathbf{1 2 2}$. The wine exports of Spain have been modelled as seasonal ARIMA(0,1,1)(0,1,1)[12], with two AOs (at $\boldsymbol{t}=\mathbf{8 0}$ and $\boldsymbol{t}=143$ ) and an LS from $\boldsymbol{t} \geq \mathbf{1 2 1}$. Table 1 reports the results of the selected models.

Table 1 Seasonal arima modelling of wine exports from France, Italy, and Spain to Japan, January 2002 - January 2020

\begin{tabular}{llll}
\hline & France & Italy & Spain \\
\hline ar1 & 0.174 & -0.763 & \\
& $(0.067)$ & $(0.108)$ & \\
ar2 & 0.141 & & \\
& $(0.069)$ & & -0.907 \\
ar3 & 0.357 & & $(0.030)$ \\
ma1 & $(0.068)$ & 0.923 & \\
ma2 & & $(0.114)$ & \\
& & 0.320 & \\
& & $(0.094)$ & \\
& & &
\end{tabular}




\begin{tabular}{|c|c|c|c|}
\hline ma3 & & $\begin{array}{l}0.311 \\
(0.079)\end{array}$ & \\
\hline sma1 & $\begin{array}{l}-0.696 \\
(0.075)\end{array}$ & $\begin{array}{l}-0.633 \\
(0.071)\end{array}$ & $\begin{array}{l}-0.610 \\
(0.065)\end{array}$ \\
\hline A01 & $\begin{array}{l}-0.559 \\
(0.122)\end{array}$ & & $\begin{array}{l}0.887 \\
(0.167)\end{array}$ \\
\hline AO2 & & & $\begin{array}{l}1.135 \\
(0.166)\end{array}$ \\
\hline LS & & $\begin{array}{l}0.386 \\
(0.045)\end{array}$ & $\begin{array}{l}0.285 \\
(0.078)\end{array}$ \\
\hline SLS & $\begin{array}{l}-0.339 \\
(0.094)\end{array}$ & & \\
\hline drift & $\begin{array}{l}0.002 \\
(0.000)\end{array}$ & & \\
\hline Log Likelihood & 103.45 & 102 & 43.38 \\
\hline$\sigma^{2}$ & 0.020 & 0.020 & 0.036 \\
\hline$A I C_{c}$ & -190.1 & -189.4 & -74.31 \\
\hline
\end{tabular}

AO: Additional outlier; LS: Level shift; SLS: Seasonal level shift. Refer to section 3 for details about the outliers.

We tested the residuals with the Ljung-Box test and the Jarque-Bera test. For the residuals of the SARIMA model of France, there is a significant spike in the ACF but the Ljung-Box test does not show lack of _t in our model ( $p$-value is 0.09377) (figure 3a). For the residuals of the SARIMA model of Italy, all the spikes are within the significance limits and the Ljung-Box test shows that the residuals have no remaining autocorrelations ( $p$-value is 0.3892 ) (figure $3 \mathrm{~b}$ ). Figure 3c shows the residuals analysis for the residuals of the SARIMA model of Spain. There are a few significant spikes in the ACF, and the model fails the Ljung-Box test ( $p$-value is 0.03067). The model can still be used for forecasting, but the prediction intervals may not be accurate due to the correlated residuals (Hyndman and Athanasopoulos, 2018).

On the other hand, the p-values for the Jarque-Bera test are $0.2968,0.6031$, and 0.6982 for residuals of the SARIMA model of France, Italy, and Spain, respectively, confirming the normalization of the residuals.

Figure 3 Residuals analysis of the SARIMA model of wine exports from France, Italy, and Spain to Japan, January 2002 - January 2019- January 2019, (log series)
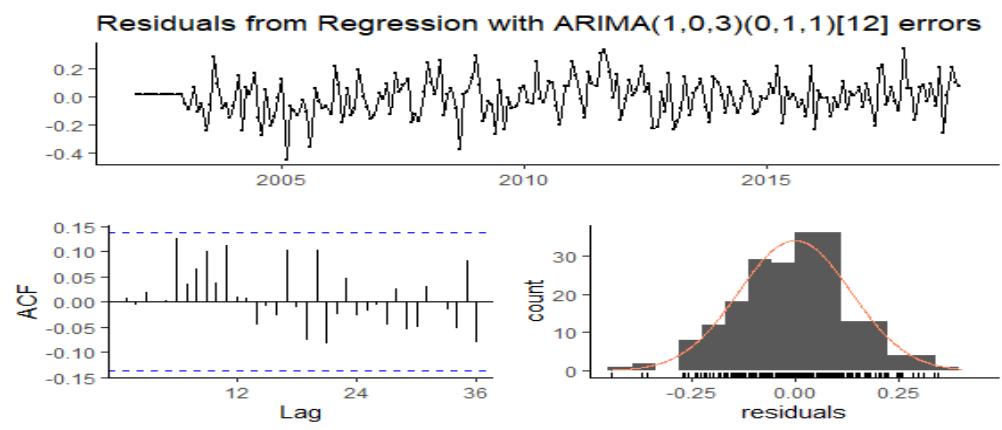
(a) France

Residuals from Regression with $\operatorname{ARIMA}(3,0,0)(0,1,1)[12]$ errors
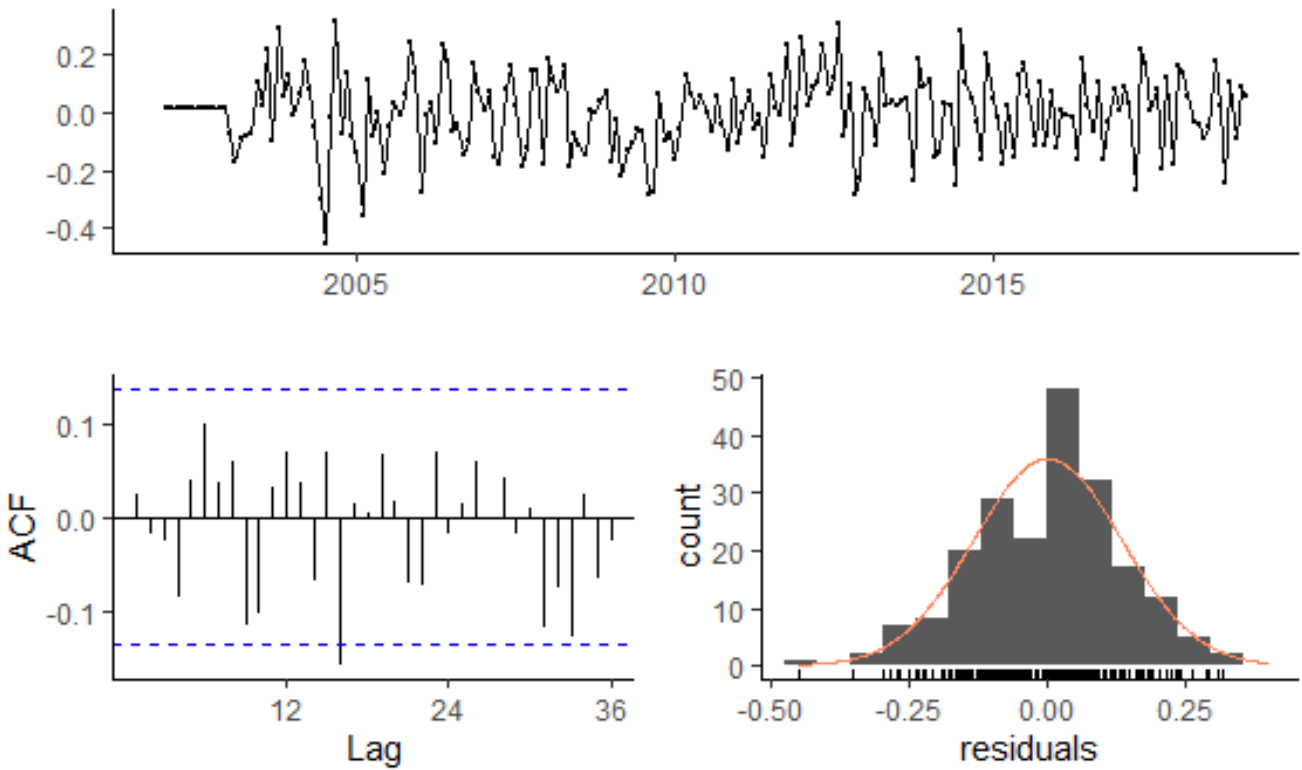

(b) Italy
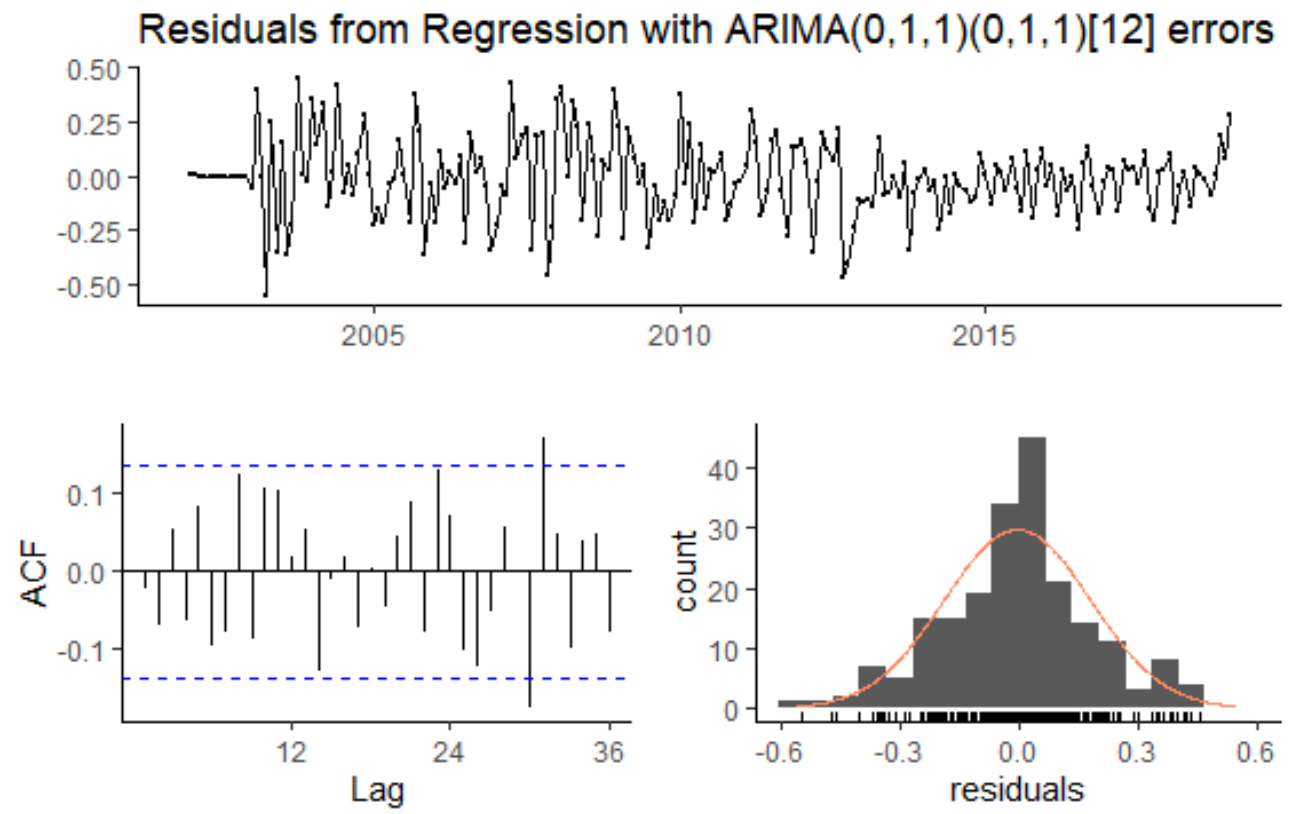

(c) Spain 


\section{Forecasts and Discussion}

Using the estimated models, we forecast twelve months ahead starting from February 2019, i.e., from the first month of implementation of the EU - Japan EPA. Subsequently, we compare the forecasts with the observed values for the same period.

Before discussing the results of the forecasts, we should highlight a potential flaw of the following analysis, i.e., we cannot forecast under the assumption of no agreement between the EU and Japan. Since the implementation of the agreement was announced in advance, the EPA could have produced anticipatory effects. Table 2 compares the exports of wine from France, Italy, and Spain to Japan in the four months preceding the entry into force of the EU - Japan EPA with those in the same months in previous years. The data for Italy and Spain do not seem to significantly differ from the pattern of the previous years for the same months. In the case of France, we observe a larger decrease in December 2018 compared with the same month of the previous year. However, a decrease of the same magnitude has been observed between December 2014 and December 2015. Consequently, we decided to forecast without including any anticipatory effects of the EPA, but this aspect should be considered while analysing the results.

Table 2 Exports of wine in the four months preceding the entry into force of the EU - Japan EPA (EUR million)

\begin{tabular}{|c|c|c|c|c|}
\hline & October & November & December & January \\
\hline \multicolumn{5}{|l|}{ France } \\
\hline $2014 / 15$ & 59.3 & 39.1 & 40.4 & 29.7 \\
\hline $2015 / 16$ & 67.8 & 39.9 & 38.3 & 26.7 \\
\hline 2016/17 & 53.4 & 40.0 & 41.4 & 27.4 \\
\hline 2017/18 & 68.8 & 39.1 & 45.2 & 35.0 \\
\hline 2018/19 & 74.1 & 39.5 & 43.1 & 34.7 \\
\hline \multicolumn{5}{|l|}{ Italy } \\
\hline 2014/15 & 13.8 & 8.5 & 11.5 & 8.8 \\
\hline $2015 / 16$ & 13.5 & 8.0 & 13.8 & 7.4 \\
\hline 2016/17 & 14.3 & 9.2 & 12.9 & 8.3 \\
\hline 2017/18 & 12.8 & 12.5 & 13.6 & 9.6 \\
\hline 2018/19 & 13.7 & 12.3 & 13.9 & 10.7 \\
\hline \multicolumn{5}{|l|}{ Spain } \\
\hline 2014/15 & 9.6 & 4.4 & 6.1 & 5.6 \\
\hline $2015 / 16$ & 8.6 & 4.9 & 6.5 & 5.5 \\
\hline 2016/17 & 9.3 & 4.1 & 5.8 & 5.8 \\
\hline 2017/18 & 7.8 & 4.5 & 6.1 & 6.2 \\
\hline $2018 / 19$ & 8.6 & 5.3 & 6.4 & 7.8 \\
\hline
\end{tabular}


Figure 4a shows that the observed values for wine exports from France to Japan outperform the forecasts for all the months except November and December 2019. In details, we observe the largest differences between observed values and forecasts in May and August 2019 (EUR 13.3 million) and the smallest differences between those in October 2019 (EUR 2.9 million) and January 2020 (EUR 2.1 million). Overall, we quantify the positive effect of the tariff removal in the first 12 months of the implementation of the EPA for wine exports from France to Japan in EUR 55.8 million.

Our forecasts for wine exports from Italy to Japan never outperform the observed values (figure 4b). In September and December 2019, we record the smallest differences, EUR 330 thousand and EUR 450 thousand between observed values and forecasts, respectively. On the other hand, the largest differences are recorded in June 2019 (EUR 2.9 million) and January 2020 (EUR 3.7 million). Overall, the total positive effect due to the tariff removal can be quantified in EUR 25.6 million.

Finally, figure 4c shows the forecasts for wine exports of Spain. In February and July 2019, we record the largest differences between observed values and forecasts, EUR 2.5 million and EUR 3 million, respectively. The smallest differences are recorded in October and November, EUR 92 thousand and EUR 53 thousand, respectively. In addition, in November 2019 and January 2020, the forecasts outperform the observed values. In the case of wine exports of Spain, we quantify the positive effect of the tariff removal in EUR 11.5 million.

From figure 4, it also emerges that the largest effect of the tariff removal is recorded in the first two quarters of the year as our forecasts can better approximate the observed values in the third quarter of the year for all the three series of data.

Figure 4 Wine exports from France, Italy, and Spain to Japan: Forecast vs Observed values (EUR)

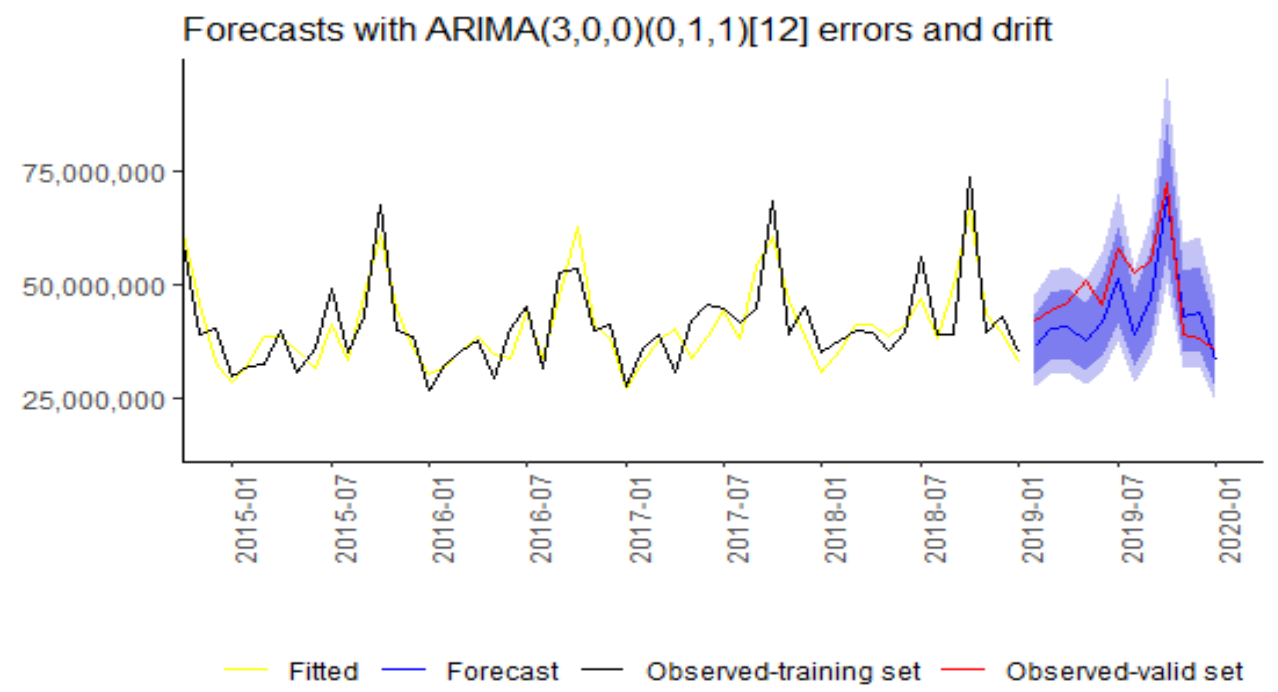

(a) France 


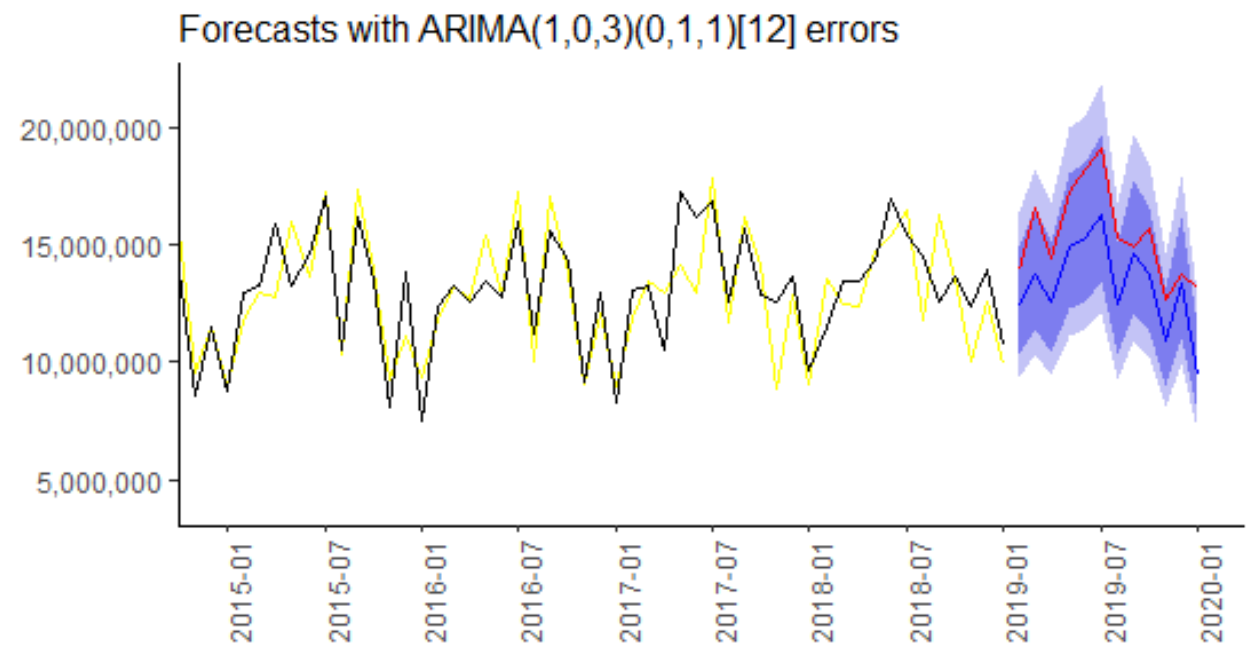

Fitted - Forecast - Observed-training set - Observed-valid set

(b) Italy

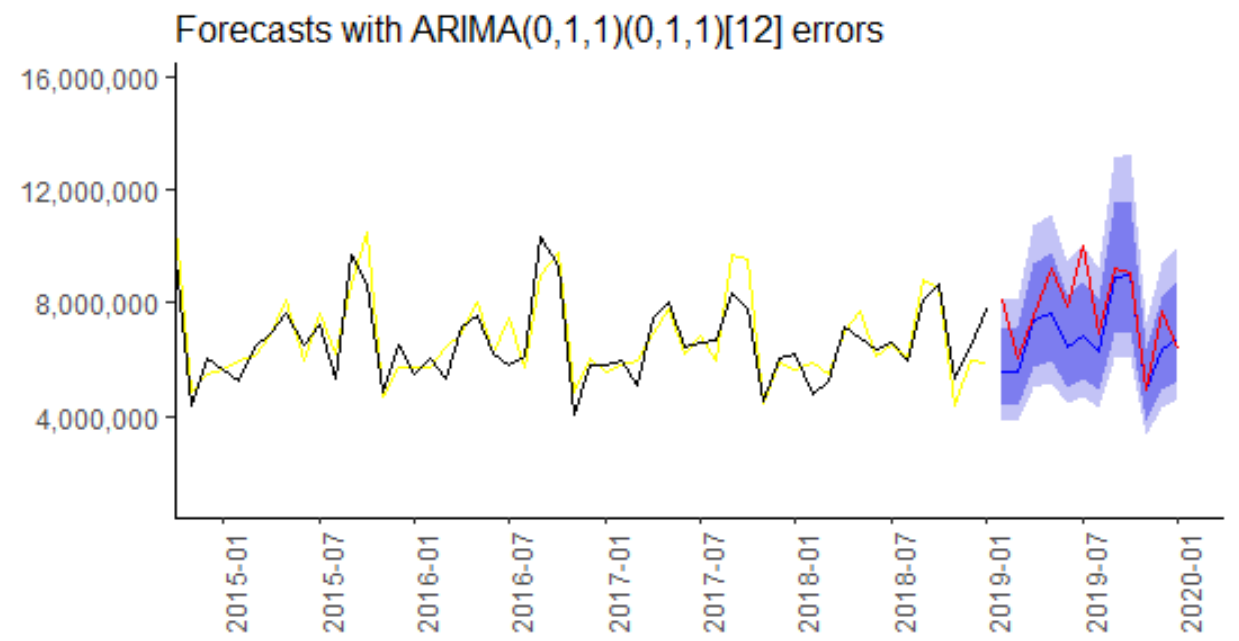

Fitted — Forecast - Observed-training set - Observed-valid set

\section{(c) Spain}




\section{Conclusion}

In this paper, we fit a SARIMA model to the monthly exports of wine from France, Italy, and Spain to Japan from January 2002 to January 2019. Subsequently, we used the estimated models to forecast twelve months ahead from February 2019, the first month of implementation of the EU - Japan EPA. We conclude that the tariff removal upon entry into force of the agreement had a positive effect on wine exports from France, Italy, and Spain to Japan which we quantify in EUR 55.8 million, EUR 25.6 million and EUR 11.5 million, respectively. Finally, our results show that in the first twelve months after the implementation of the agreement, the effect of the tariff removal has been larger in the first two quarters of the year since we observed a larger difference between the observed values and our forecasts.

\section{References}

[1] Box, George E.P., Gwilym M. Jenkins, and Gregory C. Reinsel (2008). Time series analysis: forecasting and control. John Wiley \& Sons.

[2] Chen, Chung and Lon-Mu Liu (1993). Joint Estimation of Model Parameters and Outlier Effects in Time Series." Journal of the American Statistical Association, 88(421).

[3] Council of Ministers of Japan on the Promotion of Economic Partnership (2004). Basic Policy towards further promotion of Economic Partnership Agreements (EPAs), December 21. [Online] Available: https://www.mofa.go.jp/policy/economy/fta/policy0412.html.

[4] de Lacalle, Javier Lopez (2019). tsoutliers: Detection of Outliers in Time Series. [Online] Available: https://CRAN.R-project.org/package=tsoutliers. R package version 0.6-8.

[5] European Commission (2006). Global Europe: competing in the World.

[6] European Commission (2015). Trade for All: Towards a more responsible trade and investment policy.

[7] Hartman, Stephen W. (2013). The WTO, the Doha Round Impasse, PTAs, and FTAs/RTAs. The International Trade Journal, 27(5), 411-430.

[8] Hyndman, Rob and George Athanasopoulos (2018). Forecasting: principles and practice. [Online] Available:https://otexts.com/fpp2/ (03 September, 2020).

[9] Hyndman, Rob, George Athanasopoulos, Christoph Bergmeir, Gabriel Caceres, Leanne Chhay, Mitchell O'Hara-Wild, Fotios Petropoulos, Slava Razbash, Earo Wang, and Farah Yasmeen (2019). forecast: Forecasting functions for time series and linear models. [Online] Available: http://pkg.robjhyndman.com/forecast. R package version 8.8.

[10] Hyndman, Rob J and Yeasmin Khandakar (2008). Automatic time series forecasting: the forecast package for R." Journal of Statistical Software, 26(3), 1 22.

[11] JETRO (2008). How to enjoy preferential tariff rates through EPAs/FTAs. [Online] Available: https://www.jetro.go.jp/ext_images/indonesia/jiepa/index.html/EPAE.pdf .

[12] Kaiser, Regina and Agustin Maravall (1999). Seasonal Outliers in Time Series. Working Papers 9915, Banco de Espana;Working Papers Homepage, [Online] Available: https://ideas.repec.org/p/bde/wpaper/9915.html. 
[13] Kassambara, Alboukadel (2019). ggpubr: 'ggplot2' Based Publication Ready Plots. [Online] Available: https://CRAN.R-project.org/package=ggpubr. R package version 0.2.1.

[14] Ministry of Foreign Affairs of Japan (2002). Japan's FTA Strategy (Summary). [Online] Available: https://www.mofa.go.jp/policy/economy/fta/strategy0210.html.

[15] Trapletti, Adrian and Kurt Hornik (2017). tseries: Time Series Analysis and Computational Finance. [Online] Available: https://CRAN.Rproject.org/package=tseries. $\mathrm{R}$ package version $0.10-41$.

[16] U.S. Department of Transportation (2006). Estimated Impacts of September 11th on US Travel.

[17] Wickham, Hadley (2009). ggplot2: Elegant Graphics for Data Analysis. SpringerVerlag New York, [Online] Available: http://ggplot2.org.

[18] Wickham, Hadley and Jennifer Bryan (2019). readxl: Read Excel Files. [Online] Available: https://CRAN.R-project.org/package=readxl. R package version 1.3.1.

[19] Zeileis, Achim and Gabor Grothendieck (2005). zoo: S3 Infrastructure for Regular and Irregular Time Series. Journal of Statistical Software, 14(6), 1-27. 